\title{
Solvent effects in the reaction between piperazine and benzyl bromide
}

\author{
S RANGA REDDY and P MANIKYAMBA* \\ Department of Chemistry, Kakatiya University, Warangal 506009 \\ e-mail: mani_prerepa@yahoo.co.in
}

MS received 30 August 2006; revised 10 August 2007

\begin{abstract}
The reaction between piperazine and benzyl bromide was studied conductometrically and the second order rate constants were computed. These rate constants determined in 12 different protic and aprotic solvents indicate that the rate of the reaction is influenced by electrophilicity $(E)$, hydrogen bond donor ability $(\alpha)$ and dipolarity/polarizability $\left(\pi^{*}\right)$ of the solvent. The LSER derived from the statistical analysis indicates that the transition state is more solvated than the reactants due to hydrogen bond donation and polarizability of the solvent while the reactant is more solvated than the transition state due to electrophilicity of the solvent. Study of the reaction in methanol, dimethyl formamide mixtures suggests that the rate is maximum when dipolar interactions between the two solvents are maximum.
\end{abstract}

Keywords. Solvation; solvent electrophilicity; hydrogen bond donor ability; linear solvation energy relationship (LSER).

\section{Introduction}

Modelling of solvent effects is one of the most useful methods to obtain information about the mechanism of organic reactions. During the last few years special attention is being paid towards study of solvent effects on different reactions. ${ }^{1-6} \mathrm{~A}$ solvent would provide not only a background for the reaction to occur but would stabilize the reactants and the transition state by solvating them. This solvation is due to solvent-solute interactions during which a solvent can act either as a nucleophile or an electrophile by donating or accepting electron pairs from the solute. It can also form hydrogen bonds with the specific sites of the solute molecules. Any solvent dependent property like rate constant of a reaction $(Y)$ can be correlated with the solvation properties of the solvent $(x)$ using a multiparametric equation ${ }^{7}$

$$
Y=a x+b x_{2}+c x_{3}+\cdots,
$$

where $a, b, c$ are the sensitivity of $Y$ towards $x_{1}, x_{2}$, $x_{3}$, etc. From the sign and magnitude of $a, b$ and $c$ in the above equation one can get an idea about the relative solvation of the reactants/transition state when $Y$ is rate constant of the reactions. Thus the study

\footnotetext{
*For correspondence
}

of any suitable solvent sensitive property in a pure solvent provides information regarding solvation due to solvent-solute interaction. According to Golami ${ }^{8}$ solvent-solute interactions are much more complex in mixed solvents than in pure solvents due to the preferential solvation by any of the components present in the solvent mixture. Due to this, the local composition of the solvent shell will be different from that in the bulk. ${ }^{9-11}$ In addition to this in binary solvent mixtures, the solvent-solvent interactions dominate the solute-solvent interactions since solvent is present in large excess compared to solute. These solvent-solvent interactions may be due to hydrogen bond formation or due to dipolar effects which would affect the property under consideration. Thus by studying any solvent dependent property in binary solvent mixtures one can get an idea about inter solvent interactions. With this end in view these solvent-solvent and solvent-solute interactions have been estimated taking the reaction between benzyl bromide and piperazine as a model reaction.

\section{Experimental}

Benzyl bromide (Riedel), piperazine (Sd-fine) were used without further purification. The solvents methanol, $n$-propanol, $i$-propanol, $n$-butanol, $i$-butanol, benzyl alcohol, acetone, ethyl methyl ketone, dimethyl formamide, dimethyl sulphoxide, acetonitrile 
and benzonitrile were all analytical grade and of Merck or Sd-fine make. After checking their boiling points, they were distilled by literature methods wherever necessary and then used. The temperature of the reaction was maintained constant with an accuracy of $\pm 0 \cdot 5^{\circ} \mathrm{C}$ using a thermostat (INSREF make). The reactions were initiated by mixing the thermally equilibrated reactants in appropriate solvents. In the benzylation of piperazine $\mathrm{HBr}$ is liberated. Therefore the reaction was followed by measuring the conductance of the reaction mixture at different time intervals. Preliminary study indicated that the reaction is first order with respect to both the nucleophile and benzyl bromide. The reactions are studied in different solvents using $0.02 \mathrm{~mol} \mathrm{dm}{ }^{-3}$ piperazine and $0.02 \mathrm{~mol} \mathrm{dm}^{-3}$ benzyl bromide. The second order rate constants $k_{\text {II }}$ are computed from the slopes of the linear plots obtained when $C_{t} / C_{\infty}-C_{t}$ was plotted against time $t$ according to the equation ${ }^{12}$

$$
k_{\mathrm{II}}=1 / a t \frac{C_{t}}{C_{\infty}-C_{t}},
$$

where $a$ is the initial concentration of the reactants $C_{t}$ and $C_{\infty}$ are the conductances of the reaction mixture at time $t$ and at the end of the reaction. The $k_{\mathrm{II}}$ values determined from duplicate runs were found to be reproducible within $\pm 5 \%$ error.

After completion of the reaction the solution was concentrated and extracted with ether. The solid separated from ether solution was recrystallized using benzene. This had a melting point of $134 \pm 1^{\circ} \mathrm{C}$. The IR absorption spectrum (with $\mathrm{KBr}$ ) did not show any absorption around $3300 \mathrm{~cm}^{-1}$ indicating the absence of $\mathrm{N}-\mathrm{H}$ group. It had an absorption around $2800 \mathrm{~cm}^{-1}$ showing the presence of $\mathrm{N}-\mathrm{CH}_{2}$ group. ${ }^{13}$ The mass spectrum of this product shows a molecular ion peak at $267 \mathrm{~m} / z$ indicating that the product is $\mathrm{C}_{4} \mathrm{H}_{8} \mathrm{~N}_{2}$ $\left(\mathrm{CH}_{2} \mathrm{C}_{6} \mathrm{H}_{5}\right)_{2}$. This suggests that both the N-H hydrogens of piperazine ring are replaced by benzyl groups.

\section{Results and discussion}

Piperazine is a cycloaliphatic secondary amine with two -NH group. It is used as an intermediate for a wide range of pharmaceuticals, polymers, dyes, corrosion inhibitors and surfactants. The reaction between this secondary amine and benzyl bromide was studied in 12 different protic and aprotic solvents and the second order rate constants $k_{\text {II }}$ estimated are presented in table 1. Correlation of these rate constants with different solvent parameters namely polarity $(Y),{ }^{14}$ polarizability $(P),{ }^{14}$ electrophilicity, $(\mathrm{E})^{15}$ nucleophilicity (B), ${ }^{15}$ hydrogen bond donor ability $(\alpha),{ }^{15}$ hydrogen bond acceptor ability $(\beta)^{16}$ and polarity/ polarizability parameter $\left(\pi^{*}\right)^{16}$ indicated that there is poor correlation between $\log k_{\mathrm{II}}$ and any of these parameters individually as indicated by the correlation coefficients. Some of these are presented in table 2. The results given in the above table indicate that the strength of the correlation increased slightly, by using a two parameter equation (6 and 7). However the correlation is not satisfactory. When the correlation is extended using a triparametric equation involving three significant parameters $E, \alpha$ and $\pi^{*}$ (eqn. 8) there is an increase in the correlation coefficient $R$, with an explained variance of 0.85 suggesting that $85 \%$ of the data can be explained by this equation on the values given in parentheses are standard errors of the estimates. The validity of this equation is tested by $F$-test. ${ }^{17}$ The $F_{\text {cal }}$ is 13.54 while the table values is 3.27 at $1 \%$ level of significance. Another test used to test the validity of the above equation is to correlate the observed and calculated (from the above LSER) values of $k_{\mathrm{II}}$. This correlation of $\log k_{\mathrm{II}}$ (obs) with $\log k_{\mathrm{II}}$ (cal) gives the following relation

$$
\log k_{\mathrm{II}}(\mathrm{obs})=1.07 \log k_{\mathrm{II}}(\mathrm{cal}) ; r=0.99 \text {, }
$$

with an excellent correlation coefficient $r$. The significance of the individual parameters used in the above LSER is tested by Student $t$-test. ${ }^{17}$ Comparison of $t_{\text {cal }}$ with the table value (3.25) suggests that the parameters $E, \alpha$ and $\pi^{*}$ are significant at $99 \%$ confidence levels. The percentage contribution of each parameter in the above LSER is estimated by normalizing the coefficients of the parameters used. ${ }^{18}$ This analysis indicates that $E, \alpha$ and $\pi^{*}$ contribute 37,40 and $23 \%$ towards the total solvent effect on rate. The negative coefficient of $E$ in the above LSER suggests that the reactants are more solvated than the transition state due to solvent electrophilicity. The positive coefficient of $\alpha$ indicates that the transition state is more solvated than the reactants due to hydrogen bond donor ability of the solvent. The dipolarity/polarizability parameter $\pi^{*}$ also contributes, indicating that the transition state is more solvated than that of the reactants due to this property.

From these observations the following solvation model can be proposed in the dibenzylation of piperazine. 
Table 1. Second order rate constants and thermodynamic parameters [benzyl bromide - piperazine system $][B Z B r]=$ $[\mathrm{PPZ}]=0.02 \mathrm{~mol} \mathrm{dm}^{-3}$.

\begin{tabular}{|c|c|c|c|c|c|c|c|c|c|c|c|}
\hline \multirow[b]{2}{*}{ Solvent } & \multicolumn{6}{|c|}{$k \times 10^{3} \mathrm{dm}^{3} \mathrm{~mol}^{-1} \mathrm{~s}^{-1}$ at temp. $/ \mathrm{K}$} & \multirow{2}{*}{$\begin{array}{c}\mathrm{Ea} \\
\left(\mathrm{kJ} \mathrm{mol}^{-1}\right)\end{array}$} & \multirow{2}{*}{$\begin{array}{c}\Delta H^{\ddagger} * \\
\left(\mathrm{~kJ} \mathrm{~mol}^{-1}\right)\end{array}$} & \multirow{2}{*}{$\begin{array}{c}\Delta \mathrm{S}^{\neq} * \\
\left(\mathrm{JK}^{-1} \mathrm{~mol}^{-1}\right)\end{array}$} & \multirow{2}{*}{$\begin{array}{c}\Delta \mathrm{G}^{\neq *} \\
\left(\mathrm{~kJ} \mathrm{~mol}^{-1}\right)\end{array}$} & \multirow{2}{*}{$\begin{array}{c}\delta G^{\neq *} \\
\left(\mathrm{~kJ} \mathrm{~mol}^{-1}\right)\end{array}$} \\
\hline & 293 & 298 & 303 & 308 & 313 & 318 & & & & & \\
\hline Methanol & $8 \cdot 33$ & $23 \cdot 33$ & $36 \cdot 66$ & - & - & - & $76 \cdot 55$ & $74 \cdot 03$ & -28 & $82 \cdot 58$ & $0 \cdot 00$ \\
\hline Ethanol & - & - & $87 \cdot 50$ & $125 \cdot 00$ & $179 \cdot 16$ & $266 \cdot 66$ & $63 \cdot 75$ & $61 \cdot 24$ & -63 & $80 \cdot 39$ & $-2 \cdot 19$ \\
\hline$n$-Propanol & - & - & $20 \cdot 83$ & $27 \cdot 77$ & $37 \cdot 03$ & 41.66 & $31 \cdot 91$ & $29 \cdot 39$ & -180 & $83 \cdot 40$ & 0.82 \\
\hline$i$-Propanol & - & - & $8 \cdot 33$ & $10 \cdot 00$ & $11 \cdot 66$ & $13 \cdot 33$ & $23 \cdot 93$ & $21 \cdot 41$ & -195 & $80 \cdot 50$ & $2 \cdot 08$ \\
\hline$n$-Butanol & - & - & $20 \cdot 83$ & $33 \cdot 33$ & $41 \cdot 66$ & $62 \cdot 50$ & $54 \cdot 70$ & $52 \cdot 18$ & -105 & $84 \cdot 00$ & $1 \cdot 42$ \\
\hline$i$-Butanol & - & - & $6 \cdot 66$ & 11.66 & $25 \cdot 00$ & $30 \cdot 00$ & $76 \cdot 58$ & $74 \cdot 06$ & -42 & $86 \cdot 89$ & $4 \cdot 31$ \\
\hline Sec-butanol & - & - & $45 \cdot 83$ & $69 \cdot 44$ & $83 \cdot 33$ & $108 \cdot 33$ & $47 \cdot 86$ & $45 \cdot 34$ & -121 & $82 \cdot 01$ & $-2 \cdot 31$ \\
\hline $\begin{array}{l}\text { Dimethyl } \\
\text { formamide }\end{array}$ & - & - & $91 \cdot 66$ & $125 \cdot 00$ & $141 \cdot 66$ & $166 \cdot 66$ & $26 \cdot 10$ & $23 \cdot 59$ & -187 & $80 \cdot 26$ & $-2 \cdot 32$ \\
\hline $\begin{array}{l}\text { Dimethyl } \\
\text { sulphoxide }\end{array}$ & - & - & $27 \cdot 50$ & 31.66 & $46 \cdot 66$ & $71 \cdot 66$ & $67 \cdot 01$ & $64 \cdot 49$ & -43 & $77 \cdot 51$ & $-5 \cdot 0$ \\
\hline $\begin{array}{l}\text { Benzyl } \\
\text { alcohol }\end{array}$ & - & - & $38 \cdot 88$ & $41 \cdot 66$ & $52 \cdot 08$ & $61 \cdot 11$ & $23 \cdot 93$ & $21 \cdot 41$ & -201 & $82 \cdot 42$ & $-0 \cdot 16$ \\
\hline Formamide & - & - & $25 \cdot 00$ & $69 \cdot 16$ & $83 \cdot 33$ & $93 \cdot 33$ & $26 \cdot 60$ & $24 \cdot 07$ & -196 & $83 \cdot 54$ & 0.96 \\
\hline
\end{tabular}

*At $303 \mathrm{~K}$

Table 2. Results of statistical analyses in the reaction between benzyl bromide-piperazine system.

\begin{tabular}{|c|c|c|}
\hline $\log k_{\mathrm{II}}=-5 \cdot 34(4 \cdot 16)+8 \cdot 48 \mathrm{Y}(8 \cdot 88)$ & $r=0.30(0.43)$ & (1) \\
\hline $\log k_{\mathrm{II}}=-2 \cdot 10(0.80)+0.05 \mathrm{~B}(0.05)$ & $r=0.29(0.41)$ & (2) \\
\hline $\log k_{\mathrm{II}}=-0.81(0.35)-0.06 \mathrm{E}(0.03)$ & $r=0.53(0.38)$ & (3) \\
\hline $\log k_{\mathrm{II}}=-0.93(0.25)+0.75 \propto(0.38)$ & $r=0.55(0.38)$ & (4) \\
\hline $\log k_{\mathrm{II}}=-1.94(0.38)+0.81 \pi^{*}(0.51)$ & $r=0.47(0.39)$ & (5) \\
\hline $\log k_{\mathrm{II}}=-0.86(0.37)-0.02 \mathrm{E}(0.01)+0.52 \propto(0.38)$ & $R=0.56(0.29)$ & (6) \\
\hline $\log k_{\mathrm{II}}=-1.39(0.57)-0.05 \mathrm{E}(0.034)+0.70 \pi^{*}(0.52)$ & $R=0.85(0.39)$ & (7) \\
\hline $\log k_{\mathrm{II}}=-3.42(0.53)-0.37 \mathrm{E}(0.07)+4.99 \propto(1.12)+3.86 \pi^{*}(0.76)$ & $R=0.924(0 \cdot 19)$ & (8) \\
\hline $\begin{array}{lllll}t= & -6.46 & -5.04 & 4.46 & 5 \cdot 1\end{array}$ & & \\
\hline
\end{tabular}

Values in parentheses are standard errors. $F_{\text {cal }}=13 \cdot 54$

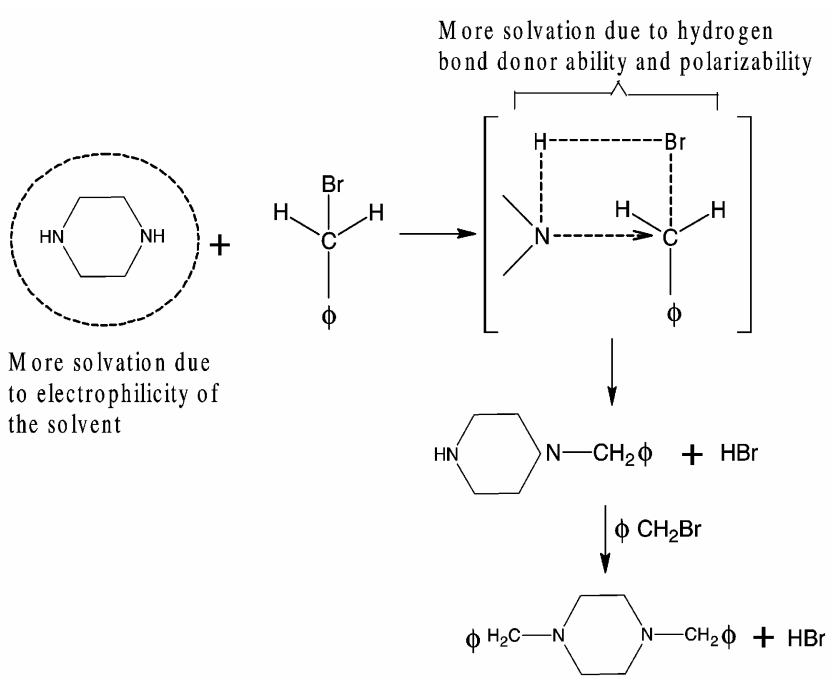

By studying the temperature effect on reaction the energy of activation $E_{a}$ and the other thermodynamic parameters $\Delta H^{\ddagger}, \Delta S^{\mp}$ and $\Delta G^{\ddagger}$ are computed and presented in table 1 . These thermodynamic parameters are strongly dependent on the nature of the solvent. In general $\Delta S^{\neq}$values are negative as expected since the transition state involves charge separation and overall solvation of the transition state as indicated by the LSER is more compared to the reactants. From the free energies of activation $\Delta G^{\neq}$is different solvents, the differential free energy of solvation $\delta \Delta G^{7}$ is evaluated ${ }^{19}$ (taking methanol as a reference) and presented in table 1. This differential solvation is a measure of extent of change in the stability of the transition state when the reaction system is changed from methanol to another solvent. These values indicate (table 1) that the transition state is more stabilized when the reactants are transferred from methanol to dimethyl sulphoxide, dimethyl formamide, ethanol and isopropanol. 
Table 3. Rate constants in solvent mixtures of $\mathrm{MeOH}$ and DMF [benzylbromide-piperazine system] [BZBr] = $[\mathrm{PPZ}]=0.02 \mathrm{~mol} \mathrm{dm}^{-3}(T=303 \mathrm{~K})$.

\begin{tabular}{lcccc}
\hline $\begin{array}{l}\% \mathrm{MeOH} \\
(v / v)\end{array}$ & $n_{\mathrm{MeOH}}$ & $n_{\mathrm{DMF}}$ & $X_{\mathrm{MeOH}}$ & $\begin{array}{c}k_{\mathrm{II}} \times 10^{2} \\
\left(\mathrm{dm}^{3} \mathrm{~mol}^{-1} \mathrm{~s}^{-1}\right)\end{array}$ \\
\hline 10 & $0 \cdot 049$ & $0 \cdot 234$ & $0 \cdot 174$ & 11.66 \\
20 & $0 \cdot 099$ & $0 \cdot 208$ & 0.322 & 23.33 \\
30 & $0 \cdot 148$ & $0 \cdot 182$ & 0.449 & 41.66 \\
40 & $0 \cdot 197$ & $0 \cdot 156$ & 0.560 & 61.66 \\
50 & $0 \cdot 247$ & $0 \cdot 130$ & 0.652 & 16.66 \\
60 & $0 \cdot 296$ & $0 \cdot 104$ & 0.741 & 7.92 \\
70 & 0.345 & 0.078 & 0.816 & 4.81 \\
80 & $0 \cdot 394$ & 0.052 & 0.884 & 3.88 \\
90 & 0.444 & 0.026 & 0.945 & 3.33 \\
\hline
\end{tabular}

\section{Effect of binary solvent mixture on rate}

The reaction between benzyl bromide and piperazine was studied in methanol dimethyl formamide mixtures of different compositions $10-90 \%(\mathrm{v} / \mathrm{v})$. The second order rate constants $k_{\mathrm{II}}$ determined at $303 \mathrm{~K}$ are given in table 3 . These values indicate that the solvent composition influences the rate in a complex way. The rate constant increases with the methanol content of the solvent mixture up to $40 \%(\mathrm{v} / \mathrm{v})$ methanol and then decreases with increase in the methanol content. The plot of $\log k_{\mathrm{II}}$ against mole fraction of methanol shows a maximum around 0.56 ( $\approx 40 \%$ methanol).

According to Bakshi ${ }^{20,21}$ dipolar protic solvents like methanol mainly undergo electrostatic interactions with other dipolar solvents through hydrogen bond formation which subsequently impart significant structural alterations in the bulk. He studied thermodynamic behaviour of methanol, dimethyl formamide mixtures by determining excess isoentropic compressibilities, excess volumes, excess viscosities, excess Kirkwood correlation factor, etc. From the study of Kirkwood correlation factor, he observed that data in methanol, dimethyl formamide mixture large aggregates of dipoles with predominantly parallel alignment are formed. Further, he observed a minimum in excess isoentropic compression and Kirkwood correlation factor at 0.55 mole fraction of methanol. This is attributed to maximum di- pole interactions at this composition. In the present kinetic study of benzyl bromide, piperazine system the maximum rate observed around this composition may be attributed to these interactions between methanol and dimethyl formamide.

\section{References}

1. Fawcett W R and Krygowski T M 1975 Aust. J. Chem. 282115

2. Ballistreri FF, Maccarone E, Masumurra G and Towasell G A 1977 J. Org. Chem. 421415

3. Reichardt C 1979 Angew. Chem. Int. Ed. Engl. 1898

4. Krygowski T M, Radomski J P, Rzeszowiak A and Wrona P K 1981 Tetrahedron 37119

5. Manikyamba P and Sundaram E V 1990 Int. J. Chem. Kinetics 221153

6. Manikyamba P 1996 Indian J. Chem. A35 334

7. Koppel I A and Palm V A 1972 Advances in linear free energy relationships (eds) N V Chapman and J Shorter (New York: Plenum Press) p 222

8. Gholami M R and Habibi Yangjeh A 2000 Int. J. Chem. Kinetics 32118

9. Marcus Y 1994 J. Chem. Soc. Perkin Trans II 1015

10. Skwierczynski D and Connors K A 1994 J. Chem. Soc. Perkin Trans II 467

11. Roses M, Rafols C, Ortega J and Bosch E $1995 \mathrm{~J}$. Chem. Soc. Perkin Trans II 1607

12. Frost A A and Pearson R G 1970 Kinetics and mechanism (New Delhi: Wiley Eastern) 2nd edn, p 37

13. Nakanishi K and Solomon P H 1977 Infrared absorption spectroscopy (Holden-Day) p 50

14. Aslam M H, Collier G and Shorter J $1981 \mathrm{~J}$. Chem. Soc. Perkin Trans II 1572

15. Koppel I A and Paju A I 1974 Org. React. (Tarter). 11137

16. Taft R W, Abboud J L M, Kamlet M J and Abraham M H 1983 J. Org. Chem. 482877

17. Shorter J 1982 Correlation analysis of organic reactivity (Research Studies Press: John Wiley and Sons) p 107

18. Ezekiel M and Fox K A 1959 Methods of correlation and regression analysis (New York: Wiley) 3rd edn

19. Jones R A Y 1979 Physical and mechanistic organic chemistry (Cambridge University Press) p 87

20. Bakshi M S, Singh J and Kaur H 1996 J. Chem. Engg. Data 411459

21. Bakshi M S and Gurinder Kaur 1997 J. Chem. Engg. Data 42298 